\title{
UNA INUSUAL ICONOGRAFÍA DE SAN PEDRO MÁRTIR EN UNA TABLA DE JUAN CORREA DE VIVAR
}

\author{
IsABel MAteo GómeZ
}

Se atribuye y suma al catálogo del pintor una pequeña tabla que, por sus dimensiones, pudo ser concebida para cumplir la devoción privada de algún fraile dominico, quien sin duda pudo sugerir al pintor la iconografía inusual representada de San Pedro Mártir.

Palabras clave: Juan Correa de Vivar; San Pedro Mártir; Pintura española; Siglo XVI.

\section{AN UNUSUAL ICONOGRAPHY FOR SAINT PETER MARTYR IN A PANEL BY JUAN CORREA DE VIVAR}

This small panel is here attributed to Juan Correa de Vivar, and added to his catalogue of works. Given its dimensions, the painting could have been made for the private devotion of a Dominican friar, who most likely would have suggested to the artist the unusual iconography involving Saint Peter Martyr.

Key words: Juan Correa de Vivar; Saint Peter Martyr; Spanish painting; $16^{\text {th }}$ century.

Entre las etapas más fructíferas de la obra del pintor toledano Juan Correa de Vivar, se halla la desarrollada entre los años 1535 y 1545 . Durante estos años el pintor lleva a cabo entre otras obras, la pintura del retablo de Meco, en la provincia de Madrid, las miniaturas en el Breviario de Carlos V, conservado en El Escorial, y los diversos retablos con los que decoró el monasterio cisterciense de San Martín de Valdeiglesias, repartidos a causa de la desamortización en el museo del Prado y, como depósito de este, en diversos museos provinciales, amén de los que pasaron a colecciones privadas de España y del extranjero ${ }^{1}$. Durante este periodo el pintor hace alarde con frecuencia de adornar sus arquitecturas utilizando columnas de mármol jaspeado en tonos verdes o rojos que contrastan con el blanco del resto del edificio, como por ejemplo en la Epifanía del retablo de Meco, y de embellecer portadas echando mano de elementos de Bramante, como en la "Puerta hermosa", donde tiene lugar la Curación del paralítico por San Pedro, que formó parte de un pequeño retablo en San Martín de Valdeiglesias, y que actualmente se encuentra en el museo de Málaga. También en San Martín de Valdeiglesias, en las tablas de la Aparición de la Virgen a San Bernardo, el pintor realza el pórtico del convento con dos cuerpos de columnas. Otra aportación del pintor en esta etapa es la de infundir a sus figuras cierto ritmo de movimiento cadencioso próximo al manierismo.

Todas las características que hemos señalado en la obra de Correa de ese periodo coinciden con las de la pequeña tablita $(46,5 \times 37,5 \mathrm{~cm})$, en colección privada madrileña, representando a Cristo caminando con la cruz por un camino y volviéndose hacia un fraile dominico que le sale al encuentro, de rodillas, en actitud orante, a la puerta del convento (figs. 1-2). El modelo de la cabeza de Cristo es exacto al que utiliza Correa para el San Martín repartiendo la capa con un pobre, de Valdeiglesias (fig. 3). No cabe duda de que la tablita que damos a conocer hoy representa en la obra de Correa, una obra de calidad y empeño, para cubrir la devoción privada de un comitente dominico, devoto de San Pedro Mártir, quien en este caso ocupa el lugar de San Pedro apóstol en el pasaje del ¿Quo Vadis?, al que luego nos referiremos. Es posible que se trate de un retrato el dominico representado, por los caracteres individuales de

${ }^{1}$ Cruz Valdovinos, J. M., "Retablos inéditos de Juan Correa de Vivar" Archivo Español de Arte, 1982, n. ${ }^{\circ} 220$, pp. 357-374. Mateo Gómez, I., Juan Correa de Vivar, Madrid, 1983, pp. 40-63. Idem, "Nueva aportación al catálogo de Juan Correa de Vivar", Archivo Español de Arte, 1988, n. ${ }^{\circ}$ 243, pp. 313-319. Idem, "La Pintura toledana en tiempos de Carlos V", EN Carlos V y las Artes: promoción artística y familia imperial, Valladolid, 2000, pp. 235-254. DocAmpo Capilla, J., "Breviario de Carlos V", en Juan Correa de Vivar, c. 1510-1566. Maestro del Renacimiento español. Toledo, Museo de Santa Cruz, 16 de diciembre del 2010 a 10 de febrero del 2011, pp. 106-108. 


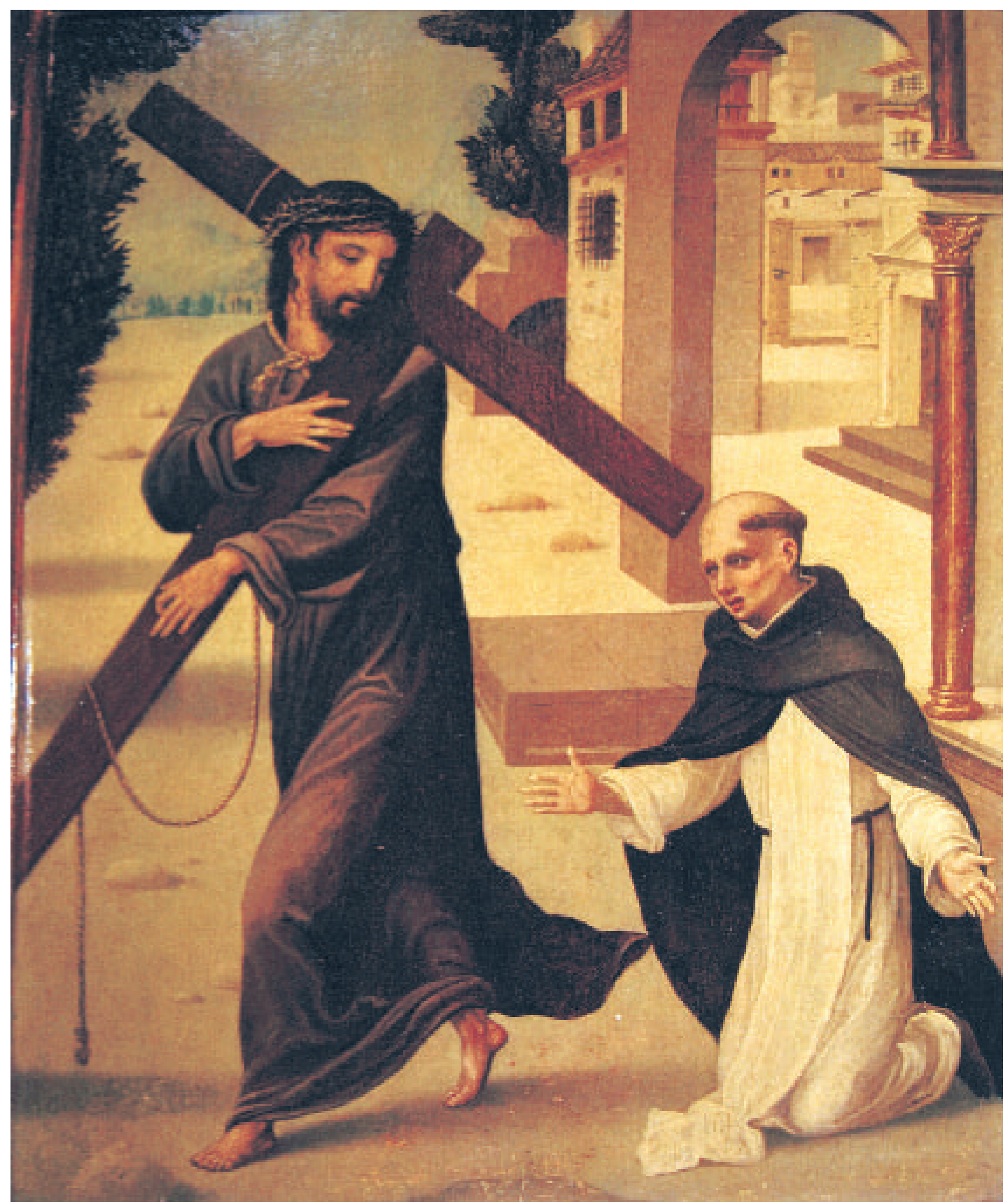

Fig. 1. Juan Correa de Vivar. Aparición de Cristo a San Pedro Mártir. Madrid. Col. privada.

su rostro y por la ausencia del nimbo, siempre presente en las representaciones del santo, recuérdense las de Pedro Berruguete y Juan de Borgoña, en el Prado. El movimiento del cuerpo de Cristo es típico del Correa de estos años, pero queremos llamar la atención de la similitud del movimiento de los pies, con los de la figura femenina que acompaña al San Marcos de 


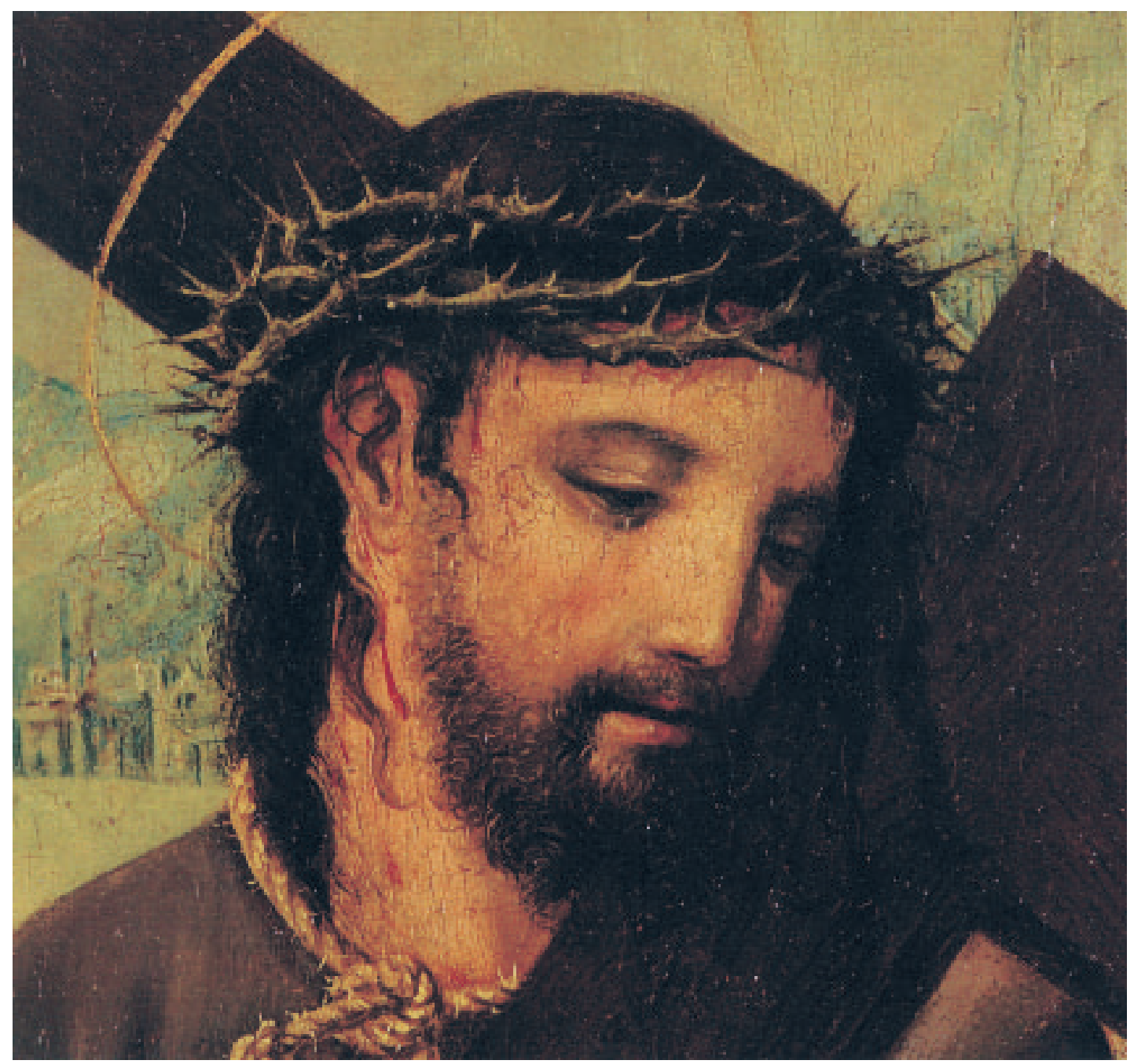

Fig. 2. Juan Correa de Vivar. Aparición de Cristo a San Pedro Mártir. Madrid. Col. privada. Detalle.

Alonso Berruguete, fechada en 1526, para el retablo de San Benito de Valladolid, movimiento que repetirá Correa en el ángel de la Anunciación del Prado, y que sin duda ofrece un sentido etéreo a las figuras.

Ya hemos aludido a la semejanza entre la escena dominica con la de San Pedro apóstol, cuando se encuentra con Cristo en la Vía Apia, después de huir de Roma a instancia de los cristianos. Al encontrarse con Cristo, San Pedro le pregunta ¿Quo Vadis?, contestándole Cristo "A Roma vengo a ser crucificado de nuevo", a lo que responde Pedro "Volveré atrás y seguirte he", cayendo en la cuenta de que el Señor se refería a su martirio, a través del cual Cristo sufría ${ }^{2}$ de nuevo la Pasión. La iconografía de la tablita de Correa debió de ser dada al

2 Actas Apócrifas, Martirio de San Pedro o Pasión de San Pedro, atribuido a Santino. La leyenda debió originarse en el siglo III, con añadidos de los siglos IV y V. El pasaje se encuentra en la primera parte del Apócrifo. 


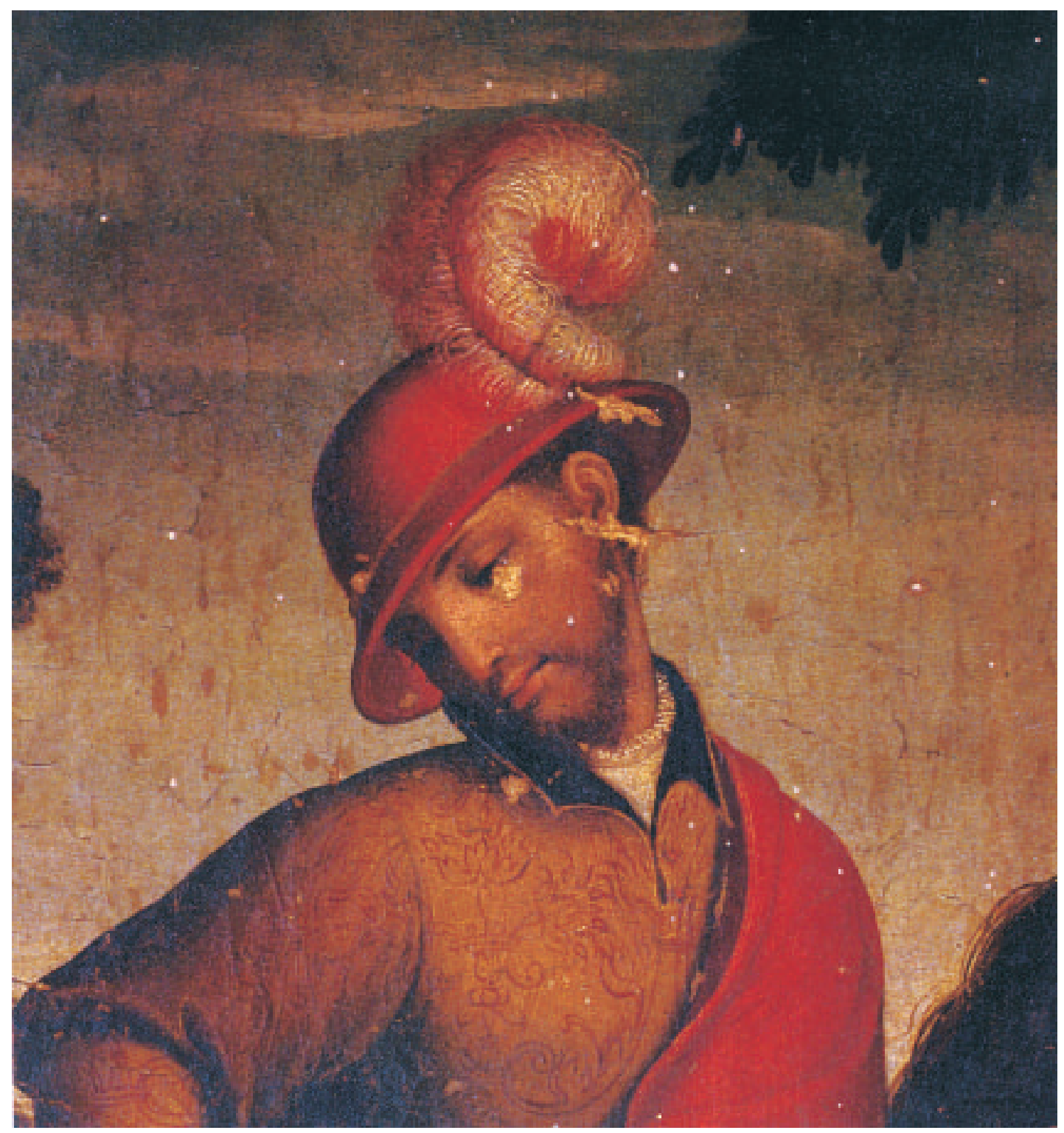

Fig. 3. Detalle de la cabeza de San Martín repartiendo la capa con un pobre. Madrid. Museo Nacional del Prado. Procede del monasterio de San Martín de Valdeiglesias.

pintor por el comitente dominico, basándose en la Leyenda Dorada, del también dominico Jacobo de Voragine, de la que existen varios manuscritos en España, uno de los cuales, el conservado en el Palacio Real de Madrid, está fechado en 1452, año en que fue martirizado San Pedro Mártir. En el manuscrito aparecen miniaturas con escenas del santo, el solo y su martirio, acompañadas por otras de la Creación (f. ${ }^{\circ} 4 \mathrm{v}$ ). En la Leyenda de Voragine sobre San Pedro de Verona, nos cuenta la semejanza que su martirio guarda con la muerte de Cristo, y cómo San Pedro en el ardor de su fe suplica al Señor beber en esta vida el Cáliz de la Pasión 


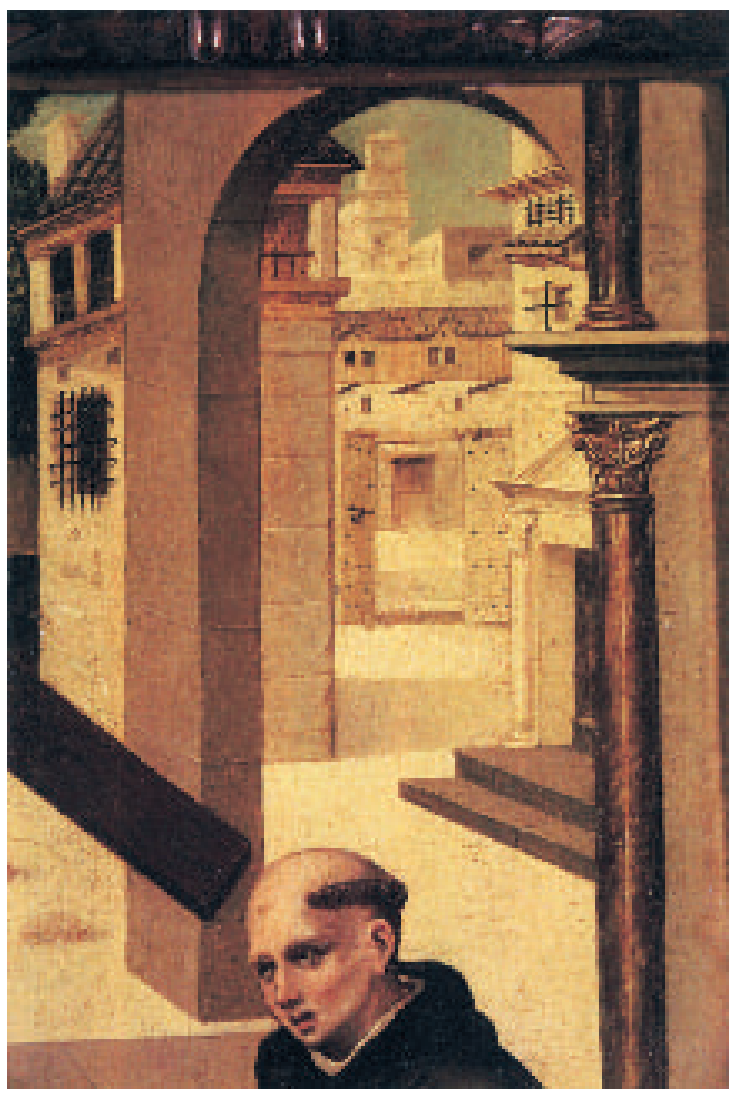

Fig. 4. Juan Correa de Vivar. Aparición de Cristo a San Pedro Mártir. Madrid. Col. privada. Detalle.

y, al ser asesinado, cuando volvía de Como a Milán, repite como Jesús "Señor en tus manos encomiendo mi alma"'s.

San Pedro Mártir fue un gran conocedor de la Biblia, un gran defensor de la fe, con una severa forma de vida, inquisidor, y, por todo ello despertó siempre la admiración entre sus hermanos de la Orden dominica de Predicadores. Por ello no nos debe extrañar que fuera encargada a Correa por algún dominico que sintiera por San Pedro de Verona una devoción particular. No sabemos a qué convento podría haber pertenecido, sin embargo nos inclinamos por el de San Pedro Mártir de Toledo, ya que la arquitectura que aparece al fondo en la tablita de Correa, concuerda con la descripción del convento, cuando los dominicos se trasladan, desde el primitivo del Granadal, al centro de Toledo en las casas cedidas por D. ${ }^{a}$ Guiomar de Meneses, agregándole casas menores, amplios patios y una calle pública ${ }^{4}$. Las columnas de mármol jaspeadas que decoran la entrada principal del templo en la tabla de Correa van rematadas por unos capiteles que el pintor utiliza en otras composiciones de por estos años, inspirándose en modelos grabados en Las Medidas del Romano, de Diego Sagredo, publicadas en Toledo en 1526, bajo los auspicios del cardenal Fonseca.

\footnotetext{
3 Voragine, J., La Legende Dorée, París, 1911, pág. 241. Formentin, J. y Martinez Murillo, M. a C., "Influencia de la Leyenda Dorada en la Literatura y en el Arte Medieval a través de dos biblias boloñesas localizadas en España", Arte Sacra, 1994, n. ${ }^{\circ}$ 93, pp. 65-139.

${ }^{4}$ Parro, S. R., Toledo en la mano, Toledo, 1857, Tomo II, pp. 57-70.
} 